\title{
Lighting design in museums: exhibition vs. preservation
}

\author{
R. Ajmat ${ }^{1,2}$, J. Sandoval ${ }^{2}$, F. Arana Sema $^{3}$, B. O’Donell ${ }^{2}$, \\ S. Gor ${ }^{2} \& \mathrm{H}$. Alonso ${ }^{2}$ \\ ${ }^{1}$ National University of La Rioja, Argentina \\ ${ }^{2}$ National University of Tucuman; Argentina \\ ${ }^{3}$ Polytechnic University of Catalonia, Spain
}

\begin{abstract}
Worldwide museums have in common the intention of "telling a story", this intention is beyond value and size of the displayed pieces, its geographical location or the quantity of people that visit them.

In this perspective, light fulfils a highly regarded double role: to reveal the object itself (physiological function) and "to generate ambience" (significance function) where the statement is produced and, therefore, it takes part of the statement in an implicit form.

However, lighting together with other environmental conditions (like temperature and humidity), can modify objects' properties significantly throughout their exhibition time, leading to deterioration. Therefore there is always a dilemma to solve: Exhibition versus Preservation. High standards of preservation may lead to poor conditions of exhibition. On the other hand, a stimulating ambience for exhibition may expose valuable objects to lower preservation standards.

This paper explores the relationship between the exhibition of artwork or historical pieces in museums and the role of lighting and other environmental conditions as generator of an ambience where a story is told. It presents surveys carried out in museums in Argentina and Spain under diverse indoor conditions. An evaluation is presented of the influence of daylighting and lighting design in museums and its relationship with other environmental conditions in the quality of exhibitions. Conclusions include recommendations for museum administrators about lighting in the exhibition of vulnerable pieces in museums.

Keywords: museums, lighting, environmental conditions, conservation, exhibition.
\end{abstract}




\section{Introduction}

Light in museums is designed to fulfil visual requirements of visitors as part of their comfort and enjoyment of the museum experience. However, visitors comfort is completely accomplished when all environmental conditions are taken into account. Environmental conditions in museums are a key element in creating the appropriate exhibition space for both: visitors and museums' collection (artwork or historic artefacts). We judge light, humidity and air temperature and pollution amongst the main museums' environmental conditions to be controlled.

Light is arguably one of the greatest causes of deterioration in museum collections, on one hand it can be destructive and thus conflicts with the museum's role in preserving our heritage; on the other it is essential to vision, the principal means of communicating the information held within and around the objects in the museum's collection. Light is a key interpretive tool to extend the potential in communication, it provides a context in time and space for the museum visitor, in an architectural sense as well as the relationship with the collection [1].

Several factors contribute to light damaging effects: the materials from which objects are made, the type and intensity of light they are exposed to and the duration of the exposure.

Especially sensitive to light are objects made of organic material documents and letters, photographs, works of art on paper, textiles, clothing and accessories. The result can be irreparable damage to museum artefacts, damage that is cumulative over the life of the objects and frequently irreversible.

The light to which museum collections are exposed is made up of three parts: ultraviolet (UV) radiation at one end of the spectrum, visible light in the middle and infrared radiation at the other end. A common misconception is that eliminating UV light solves the problem of deterioration. But all light, wherever it falls on the spectrum, is energy. And it is energy that drives the chemical reactions that result in damage to objects from fading. High-energy UV light falls outside the range of human vision and so is not necessary for viewing a museum exhibit. At the other end of the spectrum is infrared light, which produces heat damage from infrared light.

Museums environmental control involve air conditioning (cooling or heating), presence of people and lighting, all these factors disturb the natural microclimate of the area and may have a negative impact on conservation of the exhibited artefacts [2].

Some studies carried out have been based on medium and long term monitoring in order to determine by simple indicators, the quality of the microclimate in relation to the requirements to eliminate risks of preservation. The thermal quality was assessed with a performance index which expresses the percentage of time the storage required parameters are not met [3].

This research project is aiming to explore the relationship between the exhibition of the pieces in museums and the role of lighting and other environmental conditions as generator of an ambience for museum visitors. 
Museums in Argentina and Spain are analyzed through physical measurements and users' surveys.

\section{Exhibition recommendations}

The CIE (International Commission on Illumination) in its 1999 meeting in Warsaw worked on different aspects of preservation concluding with some of the following observations [4]:

Usual adopted classification systems of historical valuable exhibition pieces based upon light sensitivity do not take into account highly photosensitive materials which require very short periods of exhibition time.

The high relevance of UV rays effects leaded to underestimate the effects of visible radiation. In many cases IR radiation effects and its heating consequences have been ignored.

Only in few cases the recommended lighting doses (lux hour/ year) are effectively applied.

The procedures for the installation of the artificial lighting schemes are not practical and clear enough in many cases

CIE produced a classification of deteriorating factors in museums, Table 1 reflects CIE classification published in the guide: "Control of damage to museum objects by optical radiation" [5].

Table 1: Deterioration factors in art work pieces.

\begin{tabular}{|c|c|c|}
\hline \multirow{5}{*}{$\begin{array}{c}\text { Direct (related with the } \\
\text { irradiation from the } \\
\text { Light source) }\end{array}$} & Irradiance - Illuminance \\
\cline { 3 - 3 } & & Exhibition Time \\
\cline { 3 - 3 } & Indirect & Rectral composition of the source \\
\cline { 3 - 3 } & & Temperature \\
\cline { 3 - 3 } & & Gases in the atmosphere \\
\hline Internal or related to the art work & Nature of the material \\
\cline { 3 - 3 } & & Selective capacity to absorb energy \\
\hline
\end{tabular}

The first group can be divided into direct and indirect factors. The direct factors considered are: irradiation of energy from the light source, the length of exhibition time and the spectral composition of the source. The indirect factors considered are relative humidity, temperature and the content of gases in the atmosphere.

Among the second group it can be included: the nature of the material and its selective capacity to absorb energy. 
Traditionally maximum light levels are applied to these categories however this is a rather oversimplified approach when considering the realities of light damage. The effects of light are cumulative and the true measure of the effect of light is that of total exposure over time. In reality the commonly accepted measures of maximum light level are based on the exposure before which a detectable change would be observed over a ten year period on display. Given the relative ease with which it is now possible to measure and record data, exposure based conservation strategies are now possible and highly desirable.

Table 2: $\quad$ Materials classification based in sensitivity [5].

\begin{tabular}{|c|c|}
\hline Category & Description \\
\hline $\begin{array}{c}\text { Not susceptible to light } \\
\text { damage }\end{array}$ & $\begin{array}{c}\text { Metal most Stone , most ceramics and glass, } \\
\text { wooden objects that have largely been used } \\
\text { outdoors or have otherwise lost their natural } \\
\text { colouring through design or use etc. }\end{array}$ \\
\hline $\begin{array}{c}\text { Low Susceptible to light } \\
\text { damage }\end{array}$ & $\begin{array}{c}\text { Includes oil paintings on canvas, most wood bone } \\
\text { and Ivory and other materials painted or coloured. }\end{array}$ \\
\hline $\begin{array}{c}\text { Medium Susceptible to } \\
\text { light damage }\end{array}$ & $\begin{array}{c}\text { Includes works on paper, textiles, naturally } \\
\text { occurring dyes, Natural history exhibits including } \\
\text { fur, feather, insect and plant material etc. }\end{array}$ \\
\hline $\begin{array}{c}\text { Extremely susceptible to } \\
\text { light damage }\end{array}$ & $\begin{array}{c}\text { Textiles like silk, high risk fading colorants, } \\
\text { handwriting ink previous to 20th century }\end{array}$ \\
\hline
\end{tabular}

At a practical level objects that fall in the first category above cannot be displayed under natural lighting. The levels for these need to be set to the narrow band before the eye loses the ability to fully appreciate colours. In nature this is the early morning when the sun is just below the horizon or the evening as the sun has set, controlling natural light to these levels creates a perpetual gloom as if on a rainy winter's afternoon, conditions not conducive to feelings of comfort and well being that you wish to enjoy in a museum environment.

The second category of exhibits can be lit to levels and with sufficient variation to accommodate changing natural light conditions in a much controlled way.

The third category of objects is easily displayed under natural lighting without substantial risk of damage.

Natural daylight potentially has a major role in museum and gallery lighting however consideration has to be given to display and conservation policy and exhibition design in relation to the architecture of the proposed gallery space.

Table 3 presents values of Megalux per hour to produce a noticeable fading effect in pigments and substrates. 
Table 3: $\quad$ Mlx.h to produce noticeable fading.

\begin{tabular}{|c|c|c|c|c|c|c|c|c|c|c|}
\hline & \multicolumn{3}{|c|}{$\begin{array}{c}\text { High } \\
\text { sensitivity }\end{array}$} & \multicolumn{3}{c|}{$\begin{array}{c}\text { Medium } \\
\text { sensitivity }\end{array}$} & \multicolumn{2}{c|}{ Low sensitivity } & $\begin{array}{c}\text { Not } \\
\text { sensitive }\end{array}$ \\
\hline $\begin{array}{c}\text { Category } \\
\text { Blue wool }\end{array}$ & 1 & 2 & 3 & 4 & 5 & 6 & 7 & 8 & $>8$ & - \\
\hline $\begin{array}{c}\text { Megalux. hour } \\
\text { UV included }\end{array}$ & 0.22 & 0.6 & 1.5 & 3.5 & 8 & 20 & 50 & 120 & - & - \\
\hline $\begin{array}{c}\text { Megalux. hour } \\
\text { without UV }\end{array}$ & 0.3 & 1 & 3 & 10 & 30 & 100 & 300 & 1100 & - & - \\
\hline
\end{tabular}

\section{Data collection in museums}

Results presented in this paper are part of a research project exploring the relationship between the exhibition of pieces in museums and the role of lighting and other environmental conditions as generator of an ambience.

Data of illuminance and luminance levels, relative humidity and dry bulb temperature is being collected from 12 different museums in Argentina and Spain, for conciseness, evidence about three examples are presented in this paper: Museum of Contemporary Art (MACBA, Barcelona, Spain) Museo de Arte Contemporáneo de Barcelona; Sacred Art Museum (Tucumán, Argentina) Museo de Arte Sacro and an Archaeology Museum (Archaeology Museum, NW, Argentina) Museo de Arqueología. Data is organized following the deterioration factors described by CIE in Table 1.

\section{Results}

\subsection{External direct factors}

\subsubsection{Illuminance}

Illuminance values were measured on different artwork or historic artefacts. In Northern Argentina findings were completely diverse. Even when some of the museums were conceived originally to house a museum, exhibition conditions of illuminance were significantly different. While the Archaeology Museum has a complex infrastructure to include 24-hour environmental controlled conditions; the MAS (Sacred Art Museum) has little control over them. Furthermore, MACBA (Contemporary Art Museum in Barcelona) fulfils most of CIE recommendations, however, for this particular case an evaluation of visual adaptation to illumination levels for visitors was carried out as the potential problem in visual adaptation to illumination levels. 
Table 4: $\quad$ Classification and exhibitions conditions (Archaeology Museum).

\begin{tabular}{|c|c|c|c|}
\hline $\begin{array}{c}\text { Artefacts } \\
\text { classification }\end{array}$ & $\begin{array}{c}\text { Sensitivity to } \\
\text { radiation }\end{array}$ & Humidity & Temperature \\
\hline $\begin{array}{c}\text { Small anthromorphic } \\
\text { statues (gold, silver, } \\
\text { textiles and feathers) }\end{array}$ & Medium to High & $44 \%$ & $21^{\circ} \mathrm{C}$ \\
\hline $\begin{array}{c}\text { Sandals (leather and } \\
\text { wool) }\end{array}$ & Medium to High & $44 \%$ & $21^{\circ} \mathrm{C}$ \\
\hline $\begin{array}{c}\text { Pan and hand-painted } \\
\text { plates }\end{array}$ & Medium to High & $44 \%$ & $21^{\circ} \mathrm{C}$ \\
\hline $\begin{array}{c}\text { "Chuspa"with } \\
\text { feathers }\end{array}$ & Medium to High & $44 \%$ & $21^{\circ} \mathrm{C}$ \\
\hline
\end{tabular}

\subsubsection{Exhibition time}

Illuminance values measured on different artefacts even when below the recommendations should be considered in annual exhibition time of exposure.

The maximum value recommended of UV rays by CIE is $10 \mu \mathrm{W} / \mathrm{lm}$ (for Class 1 artefacts). If we consider one of these materials classified as "extremely susceptible to light damage", therefore its annual limit of exposure is 15000 lx.h/year. If we adopt an average value of 30 lux (like Figure 1 and Table 6) the annual possible dose with an exhibition regime of 8 hours per day throughout 260 days per year (this is to say 6 days per week over approximately 52 weeks a year). This results in 624001x h/year, which is far over the limits. Therefore for the values measured at the Archaeology Museum still some care should be taken to protect the Class 1 exhibitions.

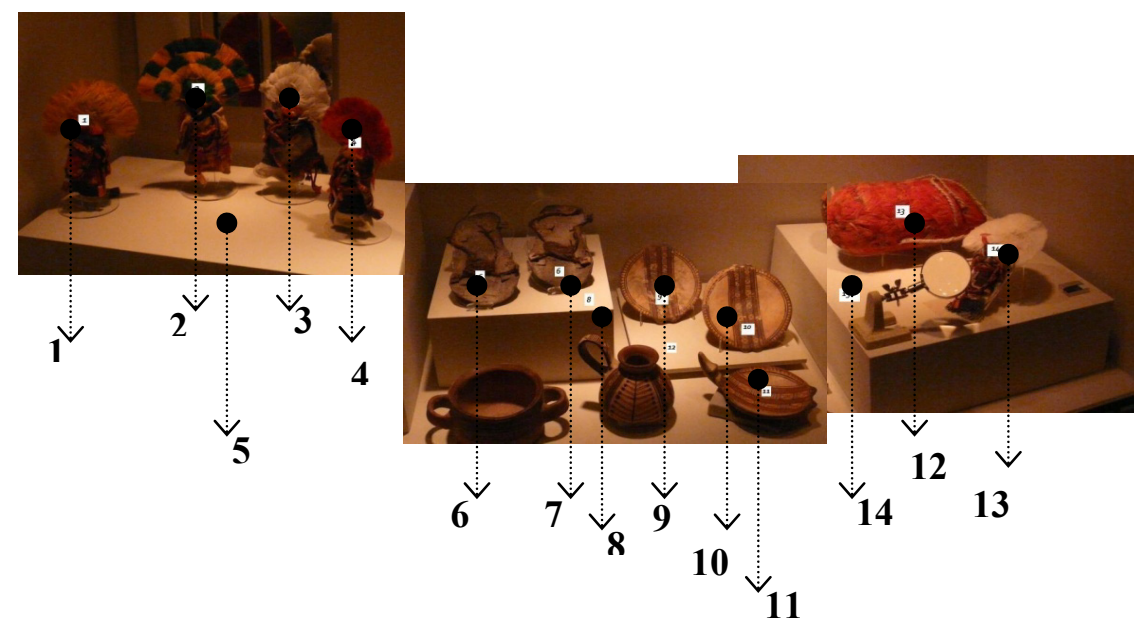

Figure 1: View of a display case at the Archaeology Museum containing artefacts with Medium to High sensitivity to radiation. 
Table 6: $\quad$ Illuminance values per point in a display case at the Archaeology Museum.

\begin{tabular}{|c|c|c|c|c|c|c|c|}
\hline Artefact & 1 & 2 & 3 & 4 & 5 & 6 & 7 \\
\hline Illuminance & 12 & 23 & 22 & 23.5 & 18.5 & 30 & 50 \\
\hline Artefact & 8 & 9 & 10 & 11 & 12 & 13 & 14 \\
\hline Illuminance & 76 & 38.6 & 44 & 17 & 30.1 & 11 & 30 \\
\hline
\end{tabular}

On the other hand, if we consider MAS exhibitions which are on display at high levels of illuminance Figure 2 (418 lux for XIX century manuscripts); these could not be exhibit any more. 418 lux by 2080 hours per year means 86.9 Mlux.h/year which is over the consideration for class 6 (the lowest at medium sensitivity materials)

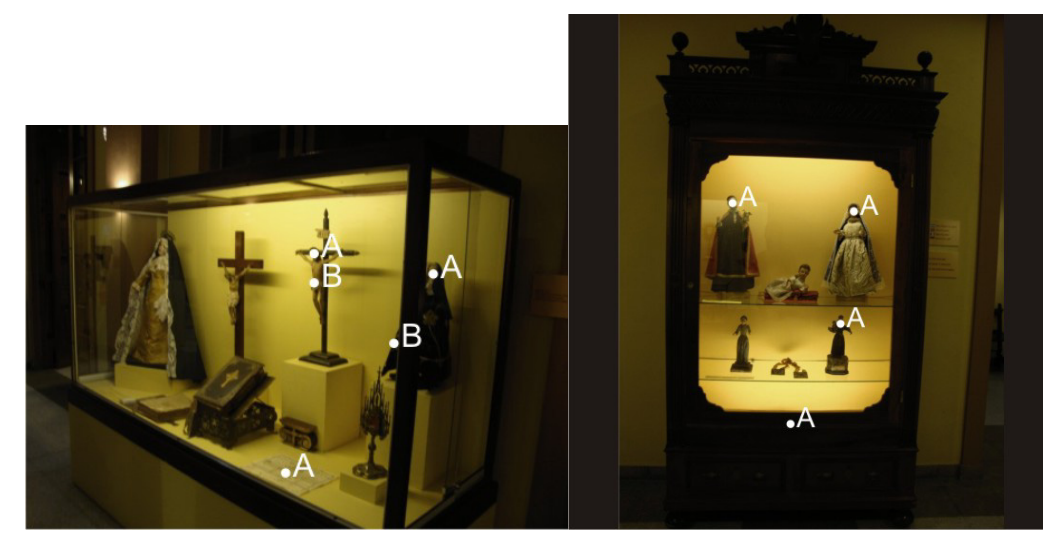

\begin{tabular}{|c|c|c|}
\hline & A & B \\
\hline Manuscript & 418 & \\
\hline Virgin & 358 & 408 \\
\hline Cross & 826 & 678 \\
\hline
\end{tabular}

\begin{tabular}{|c|c|}
\hline Textile & 1370 \\
\hline Wooden image & 436 \\
\hline St. Joseph & 850 \\
\hline Virgin Mary & 951 \\
\hline
\end{tabular}

Figure 2: $\quad$ Illuminance values for two display cases at MAS.

\subsubsection{Spectral composition of the sources}

Luminous sources to be used in museums and art galleries are a major concern for lighting designers. Much attention should be paid to the luminous capabilities of different types of sources in order to achieve proper lighting conditions for the objects exhibited to be appreciated. On that behalf, within the same research project we analyze some of the most usual luminous sources used in museum lighting systems: incandescent halogen with metallic reflector, LED based lamps and compact fluorescent lamps, comparing their Spectral Power Distributions (SPDs) and considering their interaction with sensitive objects. 
The white LED lamp seems to be the most suitable lamp to be used for this application, because of its low content of undesirable radiation (UV and IR) compared with the amount of emitted radiation in the visible range of the spectrum [6]. Proportions of UV/IR/VIS in the emission are, respectively, of $0.01 \%, 0.95 \%$ and $99.04 \%$. These figures make the LED lamp perfectly adequate for its application in museum lighting. Most of the radiation of this lamp type is emitted in the visible portion of the spectrum, dividing it up in the three main bands of the spectrum as follows: Red $=59 \%$, Green $=26 \%$ and Blue $=$ $15 \%$. This means that hardly one fourth of the emission is located at the central portion of the visible spectrum, where the radiation is highly effective for vision. However, due to its negligible level of harmful radiation, this lamp appear as a main choice when lighting designers have to select luminous sources for their projects when the main objective is to preserve objects and avoid damage.

Incandescent halogen lamp with metallic reflector (AR111 or similar), has many advantages as a luminous source: easily available and replaceable, different existing powers, pleasant and warm visual appearance. However, it has several disadvantages, its comparative low luminous efficacy, for instance, or its inadequate distribution of the emission for applications where sensitive objects have to be illuminated. Corresponding ratios of UV/IR/VIS for this lamp type are respectable: $0.23 \%, 62.76 \%$ and $37.01 \%$ whilst its distribution within the visible range is $\mathrm{R}=77 \%, \mathrm{G}=15 \%$ and $\mathrm{B}=8 \%$. As can be easily seen, the emission in the UV region $(0.23 \%)$ is almost as negligible as in the case of LED lamp, being its content in the visible region remarkably lower than that (37.01\% vs. $99.04 \%)$. This unwanted characteristic can be overcome by increasing the number of lamps used, nevertheless on doing this, another problem arises: the emission of the lamp in the IR region is extremely high $(62.76 \%)$ and if the number of lamps is increased the risk of damage of the illuminated objects could take an unacceptable high level.

Compact fluorescent lamps (CFL) warm white 45W CFL. Its SPD shows that $1.58 \%$ of the emission is in the UV, $2.68 \%$ in the IR and $95.74 \%$ in the VIS region of the spectrum which distribution is $\mathrm{R}=43 \%, \mathrm{G}=30 \%$ and $\mathrm{B}=27 \%$. The use of such lamp does not seem to be a problem from the point of view of its IR content either, generally speaking, due to its UV content. This could be a reasonably choice, especially for general lighting applications.

\subsection{External indirect factors}

\subsubsection{Humidity}

Relative humidity ratio analyzed in the Archaeology Museum has very little variations around $44 \%$ throughout the day which guarantees stable and adequate conditions.

In the case of the Sacred Art Museum, where no controls are in practice, measurements were taken in the general exhibition space and within one of the display cases where high sensitivity material is displayed. These measurements are compared with simultaneous data from the exterior (Figure 3). Evidence is presented that variations from exterior humidity are higher than interior ones, however the lower rate of internal values exceed $50 \%$ and go up to $70 \%$. 


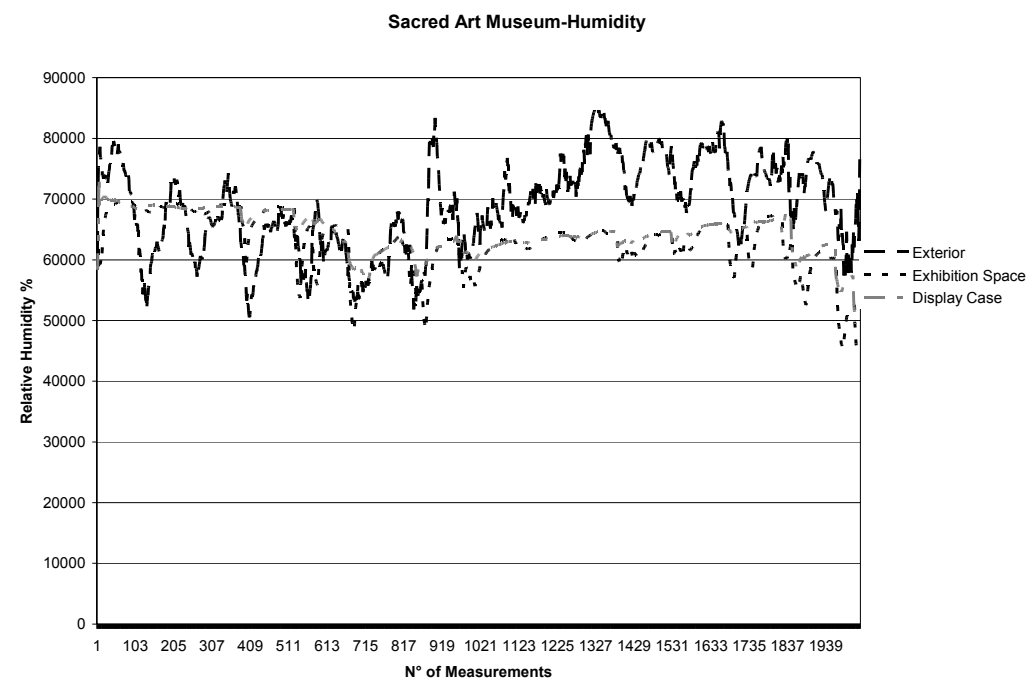

Figure 3: $\quad$ Measured values of $\mathrm{HR} \%$ at MAS.

\subsubsection{Temperature}

Analyzing the Temperature values was found that Archaeological Museum with a 24 hour control system has very little variations around $22{ }^{\circ} \mathrm{C}$ throughout the day which guarantees acceptable and stable.

In the case of the Sacred Art Museum, measurements were taken in the general exhibition space and within one of the display cases where high sensitivity material is displayed. These measurements are compared with simultaneous data from the exterior (Figure 4). Evidence is presented that peaks

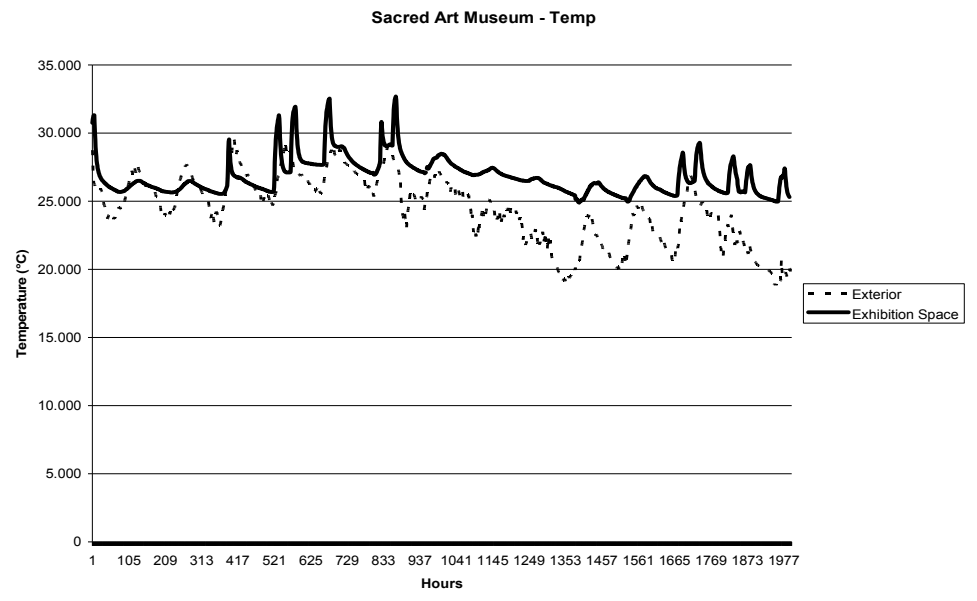

Figure 4: $\quad$ Measured values of temperature at MAS. 
registered from interior temperature are higher than exterior ones. Internal values exceed largely $22^{\circ} \mathrm{C}$ and over $30^{\circ} \mathrm{C}$ at various times. Building envelope is preserving heat inside and this is clearly noticed in measurements.

\subsection{Evaluation of visual adaptation to illumination levels}

An evaluation of visual adaptation to illumination levels was conducted at the Contemporary Art Museum of Barcelona (MACBA) [8].

The potential problem in visual adaptation to illumination levels was located at the transition from the entrance atrium and ramps, a bright white lobby illuminated by both daylight and artificial light, to the 1st floor exhibition room, illuminated with low illumination levels for purposes of preserving category 1 exhibition objects and normative requirements.

A clear pathway for visitors had been established by both architectural layout and curator's decisions on door openings, providing two clearly different zones: The atrium and ramp-stairs zone and the exhibition rooms only separated by a $2.00 \mathrm{~m}$. by $5.00 \mathrm{~m}$.corridor. Several luminance maps were obtained by sets of five photography shots in High Resolution System (HDR) (SH1, SH2; SH3) for each map in the atrium and ramp-stairs to obtain values of luminance providing the quantitative aspect of the study as a difference of illumination between zones (Figure5). For the same aspect in exhibition rooms, information from the museum of strict matching to normative requirements was taken as valid [9], since the study attempted to evaluate the visitors response collected in qualitative terms by a series of surveys conducted in three points along the path way. The first survey point was taken at the atrium and ramps-stairs, precisely at the end of the ramp, the second survey point in the middle of the first exhibition room as the visitors had just entered, the third survey point in the last exhibition room as the visitors finish the travel, prior to their way out. The straight distance between points was approximately $30 \mathrm{~m}$. and time of travel between them was approximately from 30 to 35 minutes, after going through the video, picture, objects, installations and other features of the exhibition display.
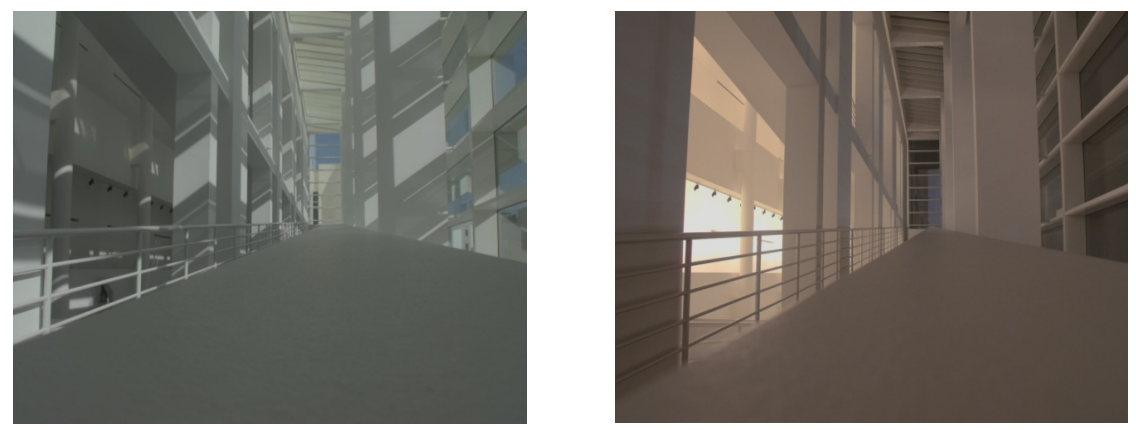

Figure 5: Left: daylight - right: artificial light. 
The survey was conducted over a population of fifty people as they travelled around the exhibition. It contained one five-graded type of question scaling visitors perception of lighting from highly illuminated at the maximum and dark at the minimum.

Table 7: $\quad$ Luminance at survey points.

\begin{tabular}{|c|c|c|}
\hline & L.max $\left(\mathrm{cd} / \mathrm{m}^{2}\right)$ & L.med $\left(\mathrm{cd} / \mathrm{m}^{2}\right)$ \\
\hline ARSZ & 5061.67 & 1092.67 \\
\hline ERZ 1 & 50 & $15-20$ \\
\hline ERZ 2 & 50 & $15-20$ \\
\hline
\end{tabular}

As expected from the high differences in the illumination of the zones, results show polarized results in the both of them, with clear differences in perceiving the environment either clear or dark in each case followed by stratification of that general perception as being irrelevant or uncomfortable, according to the percentage qualifying the extreme grades as 5 or 1.In the first case (ARSZ s1), almost one out of three visitors perceived the atrium-ramp-stairs zone as uncomfortable due to high illumination. In the second (ERZ s1) problems in adaptation are confirmed by $80 \%$ of the surveyed, estimating the environment as dark, $40 \%$ of them qualified it as uncomfortable by grading it as 1 , the minimum of the scale. At (ERZ s2) after an average of thirty minutes of adaptation period of time visitors report show a significant reduction of discomfort perception in the overall from $40 \%$ to only $10 \%$, with the majority moving towards the centre of the grading scale in which an additional $20 \%$ perceived it as clear and half of them still perceiving it darkish but not grading it as uncomfortable.

Table 8: $\quad$ Survey results.

\begin{tabular}{|c|c|c|c|c|c|}
\hline & $\begin{array}{c}\text { Highly } \\
\text { illum. }\end{array}$ & $\begin{array}{c}\text { Very } \\
\text { clear }\end{array}$ & Clear & Darkish & Dark \\
\hline ARSZ & $29 \%$ & $14 \%$ & $57 \%$ & - & - \\
\hline ERZ 1 & - & - & $20 \%$ & $40 \%$ & $40 \%$ \\
\hline ERZ 2 & - & - & $40 \%$ & $50 \%$ & $10 \%$ \\
\hline
\end{tabular}

\section{Conclusions}

Valuable data has been collected from different museums to date. Lighting parameters (illuminance and luminance values) and lighting sources choice should be carefully designed and strictly controlled while in use to protect sensitive exhibition goods and to provide comfortable exhibition conditions for visitors. LED technology seems to accomplish most of the requirements for this task. Adequate temperature and humidity rates cooperate in both preservation and comfort within museums, however still when recommendations have been met in some of the museum spaces, attention should be paid also to exhibition time. As shown, highly sensitive material should be very carefully displayed to 
avoid short term deterioration. A reasonable balance between appropriate environmental conditions and exhibition times may lead to a better preservation and quality of the visual environment. The generation of an appropriate ambience for both objects and visitors in order to provide with the "museum experience" needs the expertise of various professionals and therefore it remains as an interdisciplinary challenge.

\section{References}

[1] Kevan Shaw Lighting Design, Lecture, Forum for exhibitors in Norrkoping, Sweden, Online: www.kevan-shaw.com/ksld upload/pdf/museum lecture .pdf

[2] Camuffo, D, Pagan, E.; Bernardi, A; Becherini, F. The impact of heating, lighting and people in re-using historical buildings: a case study, Journal of Cultural Heritage, 5, pp. 409-416, 2004.

[3] Corgnati, S., Fabi, V., Filippi, M., A methodology for microclimatic quality evaluation in museums: Application to a temporary exhibit, Building and Environment, 44 (6), pp. 1253-1260, 2009.

[4] CIE Publication 89/3, On the Deterioration of Exhibited Museum Objects by Optical Radiation, 1990.

[5] CIE Publication 157, Control of Damage to Museum Objects by Optical Radiation, 2004.

[6] Thomson, Garry. The Museum Environment, Second Edition. Butterworths, London, 1986.

[7] S. Gor, J. Sandova 1, B. O’Donell, R. Ajmat, O. Alonso. Preservación de bienes culturales y elección de fuentes luminosas y materiales. Proceedings of X Congreso Panamericano de Iluminación Lux América 2010, 200-209pp, Valparaíso, Chile, 2010.

[8] F. Arana Sema, E. Ceron Palma, M. Rizzi, Evaluation of visual adaptation to illumination levels, Universitat Politécnica de Catalunya, 2009.

[9] Código Técnico de la Edificación España, Real Decreto 1650/1977. Madrid, España, 1977. 